\title{
La edad de las Culturas Americanas.
}

Constituye el problema más difícil en la investigación de las culturas de la América antigua la constatación de su cronología absoluta. Pues no existe tn verdadero saber histórico sin esta constatación del desarrollo histórico, segín su tiempo y duración, desarrollo, cuyos exponentes exteriores no son sino las cifras que designan los años. Nuestra meta debe ser, siempre, hacer revivir delante de nuestra visión la historia hundida de estos hombres y estados, inclusive sus acontecimientos, hechos y personajes conductores, $\mathrm{y}$, a saber, en la sucesión natural de las generaciones, que soportan y representan el desarrollo. $Y$ no es que este desarrollo de las culturas americanas esté aislado, sino que forma de cualquier modo un elemento de la historia universal, en la cual el acaecer de las distintas culturas está entretejido conforme a su tiempo y a su lugar. Es más que incierto, si podremos lograr, aunque sea solamente de un modo aproximado, reconstruir este orden orgánicamente necesario. Pero la meta que nos hemos fijado: es la meta de toda la historiografía y determina los distintos problemas de la investigación, ya sean resolubles o nó.

Pues, en último término no se trata de constatar las 
"capas" de la cultura delimitándolas y comparándolas, de observar las formas de los instrumentos y de los ornamentos "en el trayecto recorrido por éllas", o de averiguar el modo como en ciertos tiempos se vivía, moraba o enterraba a los muertos-todo eso no es sino un coleccionar y ordenar del material para llegar a la verdadera meta del historiador. Es porque la prehistoria y la arqueología constituyen ciencias preliminares para el historiador, y la historia es aquello que, en tiempos pasados, sucedió efectivamente.

Debemos convencernos: no hay una cultura de bronce, ni una cultura del matriarcado o cultura de los vasos de campana, sino sólamente culturas humanas, que se forman siempre en un número reducido de generaciones, y cuyos restos accidentales únicamente son las capas y las formas ornamentales. Debemos tener plena claridad de todo lo que no nos hablan. Cuando un prehistoriador de un futuro lejano describiese el siglo XIX como la capa de los alambres de cobre y de las latas de conserva, habría olvidado precisamente lo que también i para da dinvestigación prehistórica constituye la meta drincipal in acontecer humano mismo. Es porque la constatación de la sucesión de las capas es un medio, pero no una meta. No es que migran los ornamentos y las formas de las vasijas, sino que los hombres viven y trabajan en formas, sin tener conciencia de su sentido o solamente una muty vaga. Los restos hablan de ello; han contenido en el pasado historia plena de vida, y el problema es ahora, cuanto podemos comprender todavía de su lenguaje de formas. Será muy poco, sino poseemos una cronología para darlas su sitio en la sucesión de las generaciones. Asimismo, se puede deducir muy poco de los restos corporales o del carácter y de la difusión de idiomas vivos. Pues también los idiomas migran de pueblo a pueblo y se difunden o mueren a consecuencia de acontecimientos his- 
tóricos que tenemos que conocer para poder derivar el estado posterior de uno anterior.

¿Qué conclusiones se podría sacar de la difusión actual de las lenguas romanas en América, Europa y el Asia suroriental, si nada se supiera de la historia romana y de la patria del latín en un rincón de Italia central? El saber cronológico significa más que un esquema. Las cifras que indican los años, relatan una vida, que, de hecho, ha existido. Es que tan sólo los hallazgos, ordenados cronológicamente, hacen patente su íntimo sentido. El defecto fundamental de la doctrina de los círculos de cultura, que dominó hace 20 años la investigación, era, que no relacionó con sus términos "joven" y "viejo", representaciones absolutas, comparando las capas antiguas, sin preguntar, si tenían la misma edad. Pues, lo que en las Islas Fidji significa muy antiguo, es en la China muy joven.

Mientras que los Europeos occidentales no sabíamos nada de la historia, salvo la de la Biblia, de los autores de la antigüedad y de las crónicas occidentales, acudíamos a la cronología bíblica que parte de la creación del mundo. Muy fácilmente podia ser ordenado todo to que conocíamos en estos 6,000 años. Pero este principio đe la clasificación ya no bastaba, desde que, desde hacía un siglo, comenzaron las excavaciones y el desciframiento de inscripciones originales, en Egipto, Babilonia, Grecia, la China y la India, y más aún, se inició, en todas partes, la búsqueda de hallazgos prehistóricos, escondidos debajo de la tierra.

Por la falta de cifras cronológicas legítimas y comprobadas, e impulsado por el afán germánico a lo infinito, surgió entonces el placer en estas inmensas cifras, que determinaban los años de hechos, sobre las cuales nada cierto se sabía. Entonces, en la cronología histórica, ya no importaban miles de años y en la prehistórica miliones, cuando se había encontrado huellas de un desarrollo. Contribuía 
a eso tanto la tendencia secreta de destruir la cronología cristiana en su sentido teológico, como el intento desesperado de la escuela de Darwin de fijar el desarrollo de las especies animales y vegetales, imaginado de un modo materialista y causal, no obstante que nada de eso se notaba en espacios temporales mensurables.

El despilfarro de las grandes cifras ha acabado hoy. Tan pronto que se encontró pruebas efectivas, los milenios se reducían a medidas humanas y naturales, muy pequeñas por consiguiente. Ya no cabe fijar el tiempo de la construcción de la pirámide de Cheops, la época de los primeros legendarios, emperadores chinos y de los reyes de Babilonia muchos miles de años antes de Cristo, o de aumentar la edad de los dibujos en las cavernas de España por diez miles de años. A. Scharff, a base de datos relativos a la duración de vida de algunos personajes, que habían desempeñados cargos en la corte, durante las primeras dinastías, redujo en algunos cientos de años la misma cronología egipciana, establecida por Eduardo Meyer; y los hallazgos en las tumbas de Er, determinados poesus sdescubridores con un cierto sensagionatisme come correspondiendo a los años alrededor de 4,000, no resistieron a la crítica, y Weidner y Cristian fijaron con razón su origen alrededor de 2,600. En la China, los hallazgos de inscripciones relativas a oráculos, sobre huesos y conchas de tortugas, tanto como las excavaciones de Anderson comprobaron, que la historia real con datos y cifras auténticas no puede haber comenzado antes de I,400. Y el método de De Geer de calcular, de acuerdo con las capas anuales de la arcilla laminosa sueca la duración absoluta del tiempo placial, condujo a una reducción enorme de las tasaciones fantasmagóricas habituales. De esto, resultan períodos que al fin corresponden, según su velocidad y duración, a la naturaleza de la vida humana. A este punto, ya hace tiempo, se debía haber llegado, con- 
ducido por la experiencia histórica. Es pues, que las grandes épocas de la historia universal se realizan todas dentro de un corto plazo. Transformaciones completas de las formas artísticas, para las cuales el prehistoriador solía suponer habitualmente varias docenas de generaciones, se realizaban, a la luz de los tiempos conocidos, siempre dentro de dos a tres generaciones. Es psicológicamente imposible, que puedan haber separado algunos siglos a Rafael de Bernini, y a Lessing de Hoelderlin. El camino del estilo romano al gótico y del rococó al clasicismo es recorrido en menos de un siglo. La vastísima difusión del islam tiene lugar en apenas tres generaciones, desde la fuga de Mahoma a $\mathrm{Me}$ dina hasta la conquista de España y de la Persia oriental. Grandes ciudades, como El Amarna de los egipcios y Samara de los califas, fueron construidas y abandonadas dentro de una sola generación. Ya razones del desarrollo orgánico de estilos revelan, que Eduardo Meyer acierta al calcular el tiempo entre la dinastía VI y XII y entre la XII y XVIII en 200 años por cada período de 6 dinastías, y no Flinders Petriequitelos fuja en Iryōocaños. De este modo, la propia historia juniyersal la de das culturas superioresencuentra su sitio en el pequeño espacio que comienza en 3,00o a. Cr. Tan sólo así adquiere forma y necesidad orgánica interior. Tan sólo asi se manifiesta la grandeza magnánime y el vigor de este acontecer con plena e inexorable claridad. Las culturas de la antigüedad, de la India y de la China comienzan más o menos simultáneamente en la segunda mitad del segundo milenio: esto comprueba el hecho, de que el carro de lucha aparece como arma superior al comienzo de todas estas culturas, en forma decisiva y súbitamente. Cabe suponer, que las culturas americanas tienen un origen mucho más reciente.

Actualmente, no hay sino una clase de fantasmagóricos, que, diletantes en mayor o menor grado en este campo, 
no quieren abstenerse del juego con grandes cifras. Es el grupo de sabios y apenas sabios, que ven al hombre primitivo entregado a una continua adoración del sol, de la luna $\mathrm{y}$ de todos los astros, creyendo, que no haya pensado en otra cosa sino en la construcción de "observatorios". Y sucede entonces, que deducen de estos supuestos establecimientos, que remonten a épocas, en las cuales el sol se levantaba todavía bajo la constelación de Tauro, de lo que resultan tantos miles de años, que estos señores se deshacen de entusiasmo. Pero actualnente, ya ningún hombre cuerdo cree, que los "Stonehenge" de Inglaterra hayan sido observatorios de los primitivos germanos. Constituyen tumbas al igual a los "Cromlechs" de la Bretaña que remontan al tiempo alrededor de 2,000 a. $\mathrm{Cr}$., cuando los Germanos ni siquiera existían. $\mathrm{Y}$ del mismo modo desapareció la creencia en una astronomía prinitiva perfecta de los babilonios y de los chinos, cuyas observaciones astrológicas científicas son de un origen muy reciente.

Pero ahora cabe preguntar, ¿qué edad tienen entonces las culturas americanas? En ellas no existía una propia historiografía, y en todo caso se ha perdido para nosotros. En Méjico, donde los mayas y los aztecas constituyen una unidad de desarrollo histórico, Spinden y otros americanistas intentaron establecer a base de los datos cronológicos sobre ciertos monolitos de los mayas una relación de la cronología descubierta allí con la de Europa occidental, empresa que dichos investigadores a mi juicio llevaron a buen éxito. Resultaba entonces, que la historia de esta cultura se desarrolló en la época postcristiana. Pero tal fundamento falta para todos los pueblos, que viven más en el sur, quedando por consiguiente como única esperanza, que se consiga relatos determinados por la cronología desde afuera, eso es, de la Asia oriental, para poder enfocar cronológicamente la historia de aquel mundo. Si tampoco nada logramos en 
este sentido, debemos renunciar para siempre a un orden histórico, con la única excepción de los últimos tiempos de los Incas. Pues resulta ser solamente un producto de la fantasía lo que los frailes españoles escribieron relativo al orden de los nombres de reyes y de cifras de las dinastías.

Ahora bien, siempre se suponía, que hubieran existido relaciones de distinta naturaleza entre la China y la costa occidental de América, pero hasta hoy falta la comprobación. Al contrario, los hechos parecen oponerse a dicha hipótesis: pues se sabe, que la cultura china era absolutamente de carácter continental. Ignoraba todavía al comienzo de la época Han (200 a. Cr.), la existencia del Japón, y una relación directa con Méjico era imposible. Además, la cultura china es mucho más antigua que la mejicana. Aquella, al comienzo de nuestra era, ya ha terminado su desarrollo vital, mientras que ésta inicia entonces su ascenso. $Y$ las obras históricas chinas no contienen ni la más ligera alusión relativa al gran continente en el este. Hay otro factor a favor de la última suposición: pues es probable, que, en América del Sur, nose hạoformadol cultura superior alguna con un desarrollo histécico unitarió Cque haya abarcado mil años. Sólamente vemos en todas partes comienzos formales de semejante desarrollo, yuxta y superpuestos, y es absolutamente imposible deducir datos cronológicos absolutos de ellos mismos. Pues, como hemos dicho, una sucesión de capas no es una historia.

Sin embargo, creo, que nos queda una última oportunidad, aunque sea vaga. Si fracasamos también en ella, tenemos que renunciar a la meta propia del conocimiento histórico. No pretendo aquí establecer una hipótesis y tampoco poseo los conocimientos necesarios en el campo de la arqueología americana para comprobar ciertas relaciones. No puedo sino indicar con pocas palabras la dirección, que, acaso, puede conducir a un enlace cronológico con la histo- 
ria establecida del mundo antiguo, y no me queda sino esperar, que otros tomen este camino y obtengan resultados útiles.

Existen a lo largo de los bordes del Océano Pacífico y en sus islas, "culturas" que muestran un gran parentesco interior de sus formas: En América noroeste, en el sitio donde el Kuro Schio viniendo del Japón gana la costa, se encuentra la "cultura" de los haida, tlingit y tsiamschiam; en Méjico occidental la de los zapotecas, en la región occidental de Nicaragua la de los chorotecas y en la costa de América del Sur, fuera de muchas culturas menores, la de Nazca. De las islas en el sur debemos considerar ante todo Nuevazelandia. Nuevameclenburgo, partes de Nuevaguinea, las Islas Fidji y las de la Almirancia. Hoy, ya no debía extrañar, que raza e idioma sean distintos. Es pues que sabemos o debíamos saber, que la "raza" de los inmigrantes es asimilada muy pronto por la población encontrada, y quehecho más importante aún-cada paisaje, con sus condiciones geológicas, climáticas y biológicas, posee poderes, capaces de imprimir a cualquiera "raza" irresistiblemente los caracteres del tipo autóctono. Y respecto al lenguaje, los filólogos olvidan muy fácilmente, que los factores existentes no comprueban nada de lo que haya existido en tiempos anteriores. Naturalmente, hoy todas las tribus americanas hablan el idioma "indio" pero, cabe preguntar, ¿cómo hablaban aquéllos inmigrantes al desembarcar, puesto que hubiesen inmigrado por el mar?.

El parentesco de la forma abarca todo lo que puede compararse aún hoy: la construcción de las casas, especialmente la forma del techo, los pilares que servían al culto, los ornamentos en general, las leyendas y los mitos, la costumbre del tatuaje, del cual se sabe ya hace tiempo que constituye una unidad desde la India sureste hasta el Perú y el Japón, según su sentido y su naturaleza; y al fin la na- 
vegación, inclusive las formas de los buques, que manifiestan claramente su origen de un cierto tipo fundamental.

Me parece, que en el pasado debe haberse producido una "irradiación pacífica". En los bordes del Océano aparecen por todas partes estas "culturas", en una forma acabada. Verdad, que se puede observar cierto proceso de desarrollo, que, acaso, no es otra cosa sino la aclimatisación progresiva; pero faltan los comienzos. Deben haber ocurrido ciertos acontecimientos-probablemente en el suroeste del Pacífico-que condujeron a esta expansión por mar, la más grande que conocemos de tiempos anteriores. Naturalmente sería insensato hablar de milenios y de continentes hundidos; pues las culturas de las islas de la Polinesia son de origen muy reciente en comparación con la India y la China. ¿Pero puede averiguarse algo sobre la edad absoluta de esta expansión, que, en todas partes, debe haber ocurrido más o menos simultáneamente?.

Creo, que es posible. No hemos nombrado aún un dominio principal de esta "cultura marginal": el antiguo Japón. Aquí se encuentran los mismos tipos de las casas lacustres polinésjcas y de la forma del techo; tipos, que se han conservado estrictamente en la construcción de los templos japoneses, distinguiéndose claramente de los del norte de la China, y en los cuales los investigadores, ya hace tiempo, conocieron el origen "malayo"; además llama nuestra atención la misma costumbre del tatuaje, difundida en todas estas regiones y caracterizada por los viajeros chinos desde el siglo III como una costumbre de naturaleza extranjera de los "Wa", y, finalmente, un parentesco íntimo de los mitos y leyendas, particularmente en el círculo de las leyendas de la isla Kyushu, situada en el sur, círculo formado alrededor de la diosa del Sol, Amaterasu, en oposición al dios del Sol de Izumo en el norte, que indica ciertas relaciones con Corea y con regiones situadas aún más allá. La 
cultura china desconocía la navegación de alta mar hasta el comienzo de nuestra era por completo y no ha podido familiarizarse con élla hasta hoy. Los chinos, ni siquiera al principio de la época Han (200 a. Cr.) presumian la existencia del Japón, y, tan sólo algunos siglos después, recibieron noticias relativas a este país, por el camino sobre los estados tributarios de Corea. Entonces, las condiciones de la cultura japonesa correspondían al estado cultural de los insulanos del Mar del sur, cuando estas islas fueron visitadas por Cook. La navegación japonesa, capacitada ya, en el siglo III d. Cr., para emprender expediciones de guerra a Corea y Hainan, mantiene entonces sus relaciones exclusivamente con el sur y sureste. En el Japón mismo, se distingue en la mezcla de razas, que caracteriza la nación actual, de formas norteñas el tipo sur de Satsuma, que muestra-como dicen-influencias "malayas"; y en el idioma, producto muy afectado por los destinos históricos, se supone fuera de elementos de supuesto origen norteasiático (altaico-mongólico) un factor malayo de gran intensidad, que seguramente nunca podrá ser comprobado con exactitud, por el hecho, de que las palabras japonesas de origen antiguo pasaron a nosotros, escritas "con caracteres chinos. Cierto es únicamente, que se perciben muchos nombres y términos como palabras de origen extranjero. $\mathrm{Y}$ al designar estos elementos como "malayos" queremos indicar más un camino para la investigación que ya el hecho comprobado. En vez de "malayo" se podría decir con la misma razón "oceánico" o emplear cualquier otro término.

Ahora bien, en la historia primitiva del Japón se ofrece, de hecho, la posibilidad de comprobaciones cronológicas. Las leyendas relativas a la iniciación del imperio, conservadas en el Kojiki y Nihongi (ambas compuestas alrededor de 720 ), se pierden como todas leyendas en la neblina de la mitología, y la cronología tradicional, que comienza con el 
Jimmu legendario, alrededor de 700 a. Cr., es falsa. Sin enbargo ha sido posible deducir de éstas y otras fuentes, particularmente de los árboles genealógicos de la antigua nobleza, un gran número de datos comprobados y relacionarlos con cifras de nuestra cronología, encontrando también las paralelas en las obras históricas coreanas y chinas. Esto fué realizado ante todo por Yoshido Togo y de una manera más amplia aún por Wedemeyer en su "Japanische Fruehgeschichte". (Los primeros tiempos de la historia Japonesa, Tokio 1930). Resulta pues con toda seguridad, que los comienzos del imperio de Yamato (la actual región de Osaka) no remontan sino al principio de nuestra era; además existió todavía en el siglo III, el imperio de una reina Himiko, probablemente de raza malaya, situado en el sur de Kyushu, que influyó esencialmente la formación de la cultura japonesa. E1 hecho, de que los japoneses no tenían conocimiento de la caballería y del carro de lucha, en viva oposición al arte guerrero de los chinos, revela, que las influencias de Correa eran mucho menores en tiempos históricos de lo que se supone en igenerah. $\mathrm{Y}$ es que precisamente las armas y demás medios de guerra constituyen en la investigación de las historias primitivas un "Leitmotiv" mucho más seguro que las formas de las vasijas y de los instrumentos, hecho que hasta ahora no encontró la debida consideración. Si los resultados de la investigación se comprobaran y se confirmara mi suposición de una expansión pacífica resultaría ser la historia primitiva del Japón un instrumento seguro para efectuar comparaciones cronológicas con América del Sur. Por lo menos, sabríamos entonces, que antes de ciertos datos cronológicos, no se debe fijar el origen de ciertas capas de formas en el Perú.

Además, estas relaciones ofrecen otra posibilidad para hacer determinadas comparaciones históricas. Pues cabe la pregunta, ¿cuál ha sido la causa de la presión, ejercitada 
desde el occidente sobre las tribus de estas costas e islas? Las obras históricas de los imperios de la antigua Java (los Babads), muy poco investigadas aún, podrían dar aclaraciones sorprendentes. La historia de estos estados se inicia con la fecha de un acontecimiento desconocido, ocurrido en $78 \mathrm{~d}$. Cr., y que debe estar en relación con las conquistas por mar, que partieron del sur de la India. La civilización de la India en los siglos después de Buda condujo a la conquista de todo el Decano no ario y más aún a poderosas empresas de guerra contra la India posterior y la zona de las islas. Siguieron viviendo en la conciencia histórica de tiempos posteriores, en Java, como una misión budista, brahmánica y quizá drávida - "págana”-, que condujo a la fundación de los poderosos imperios javanesos con su grandiosa arquitectura de templos?. ¿A qué distancia hacia el oriente se había propagado este empuje? Las huellas de mitos índicos, en todo caso más de origen drávida que ario -la religión Vishnu ya no conserva nada del carácter de los Vedas-se encuentran hasta el corazón de la Polinesia, así como costumbrés, ơrnamentos, ainzas ya quizá también palabras de lenguas de la India, al igual como palabras portugueses se han conservado como el último recuerdo de su pasado poderío universal en muchos idiomas de la Asia sureste. ¿Acaso, había partido de allí el desarrollo del tipo de buque polinésico-japonés? El hecho, de que todo lo que los conquistadores españoles habían visto en el Perú, y los ingleses desde Cook en la Polinesia, no eran sino los restos de un arte en decadencia, parece revelar, que dicho tipo de buque debía su existencia a sugerencias extranjeras. Los faluchos de la Polinesia aparecen, en una forma malentendida, como ornamentos sobre los tambores de bronce de la China del sur y de Anam, de los cuales se supone que fueron creados en el primer siglo $\mathrm{d}$. Cr.

Si todos estos datos se comprobaran como verídicos, se 
nos ofrecería un medio para obtener en los dominios de las antiguas culturas del Perú, del Ecuador y de Columbia puntos de enfocamiento cronológicos, por lo menos aproximados, sirviendo de base para un orden histórico de las "capas de cultura". En todo caso se comprobaría, que tanto aquí como en Méjico el propio desarrollo no había abarcado mucho más de mil años y que tuvo lugar esencialmente en el primer milenio $d$. Cr.

Concluyendo, vuelvo a repetir: No he intentado otra cosa sino señalar posibilidades, convencido de que las comparaciones cronológicas constituyen la última clave para el orden y la comprensión de la historia que, en el pasado, tenía aquí su escenario. $Y$ cabe esperar, que tomando dicho camino se desvanezca la obscuridad que oculta esta historia.

Traducido de la revista: "Ibero-Amerikanisches Archiv", año VII, No.2.

\section{Biblioteca de Leswatid Spengiter. "Jorge Puccinelli Converso"}

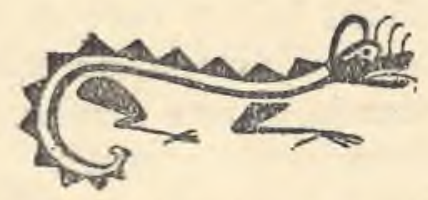

